\title{
Physical capital, knowledge capital, and the choice between FDI and outsourcing
}

\author{
Yongmin Chen Department of Economics, University of \\ Colorado, Boulder \\ Ignatius J. Horstmann Rotman School of Management, \\ University of Toronto \\ James R. Markusen Department of Economics, University of \\ Colorado, Boulder
}

Abstract. There exist two approaches in the literature concerning the multinational firm's mode choice for foreign production between an owned subsidiary and a licensing contract. One approach considers environments where the firm transfers primarily knowledge-based assets and assumes that knowledge is non-excludable. A more recent approach takes the property-right view of the firm and assumes that physical capital is fully excludable. This paper combines both forms of capital assets in a single model. There are subtleties, and added structure is needed to establish what ex ante seems a straightforward testable hypothesis: relatively physical-capital-intensive firms choose outsourcing while relatively knowledge-capital-intensive firms choose FDI. JEL classification: F2, L2

Capital physique, capital de connaissance, et le choix entre l'investissement direct à l'étranger et la sous-traitance. Il existe deux approches dans la littérature spécialisée quand on examine les choix de production à l'étranger d'une firme plurinationale : devenir propriétaire d'une filiale ou entrer dans un contrat de sous-traitance. Une approche prend en considération les environnements où la firme transfère surtout des actifs basés sur la connaissance et présume qu'on ne peut exclure les tiers de la connaissance. Une approche plus récente adopte une approche à la firme en termes de droits de propriété et assume qu'on peut exclure pleinement les tiers de la propriété du capital physique. Ce mémoire tient compte des deux formes d'actifs dans un même modèle. On doit ajouter des subtilités et une structuration additionnelle pour établir ce qui semble ex ante une hypothèse relativement simple et vérifiable: les firmes à forte intensité relative en capital physique choisissent la sous-traitance pendant que les firmes à forte intensité de capital de connaissance choisissent l'investissement direct à l'étranger.

Markusen is also affiliated with the School of Economics, University College Dublin, NBER, and CEPR. We thank two referees and participants at a number of seminars and conferences for helpful comments and suggestions. Presentations were at the NBER ITO Working Group Meeting in Cambridge, the ERWIT conference in Appenzell, the ETSG conference in Warsaw, and the Norface conference in Munich, all held in 2008, and the Swiss Federal Institute of Technology and Hitosubashi University, Japan, held in 2009. Email: yongmin.chen@colorado. edu; Ihorstmann@Rotman.utoronto.ca; james.markusen@Colorado.edu 


\section{Introduction}

Many of the most popular lines of Crocs footwear are injection-moulded and assembled by a contract manufacturer in China. By contrast, the manufacture of the crosslite pellets used to produce the rubbery material from which Crocs are made has moved from outsourced production to being produced in house by Crocs. Intel manufactures chips in China but does so in Intel-owned operations. In all of these cases, the manufacturing processes employ quite sophisticated equipment and are reasonably capital-intensive. Still, the manufacture of Crocs clogs is outsourced, while the manufacture of chips and crosslite takes place in house.

In this paper we argue that it is not so much differences in physical capital (relative to labour) intensity that drive the outsourcing decision but rather differences in knowledge capital (relative to physical capital) intensity. The key difference, we argue, between physical and knowledge capital is that it is relatively easy for the owner of physical capital to specify and monitor the uses to which physical capital is put: ownership of physical capital bestows significant control. By contrast, it is often relatively difficult for the owner of knowledge capital to specify and control fully the uses to which this capital is put. When production returns are generated largely by knowledge capital rather than physical capital, ownership of and so control over the physical capital become a (second best) way for the owner of the knowledge capital to exercise control over it. The result is that production takes place in house. When the opposite is true - production returns are driven largely by physical capital rather than by knowledge capital then it is inefficient for the owner of the knowledge capital to also own the physical capital and so outsourcing occurs.

To make these arguments formal, we develop a simple two-period incompletecontracting model. A firm requires both physical and knowledge capital for a foreign subsidiary, along with non-contractible effort by a foreign licensee or manager. Effort is relatively more important as a complement to physical capital than knowledge capital, creating the well understood advantage for using a licensee who owns the physical capital and thus captures the full benefit of his or her effort. However, knowledge capital transferred by the multinational is absorbed by the licensee during the first period regardless of who 'owns' it. We assume that the value of this knowledge to a manager or licensee outside the relationship depends on working with the physical capital, the two assets being complements. Thus the advantage to the multinational in owning the physical capital is that it reduces the incentives or ability of the licensee to use the knowledge for private or outside uses in period 2. Our main prediction from the analysis of this model is that, in situations in which returns are driven largely by knowledge capital, in-house production / FDI should be observed; in situations in which returns are driven largely by physical capital, outsourcing should be observed. This prediction is consistent with the anecdotes above. 
The model makes a number of other predictions. Specifically, it predicts that one should observe a positive correlation between the fraction of foreign operations that are owned by the firm (rather than outsourced) and the firm's value of Tobin's $q$. Existing evidence, reviewed in Markusen $(1995,2002)$ and Caves (2007), and new evidence in Jinji, Zhang, and Haruna (2011) support this prediction. ${ }^{1}$

The model also predicts that, over the product life cycle, one should observe foreign operations being characterized largely by FDI early on in the product life cycle - products are more knowledge capital-intensive early in the life cycle - but by outsourcing later in the life cycle. Markets in which technologies evolve rapidly, and so knowledge capital depreciates quickly, are ones in which outsourcing should be more prevalent. Finally, it predicts that outsourcing is more likely in situations in which the foreign capital markets are relatively well developed, whereas FDI is more likely when the foreign capital markets are less well developed. Similarly, outsourcing is also more likely in countries in which protections for knowledge capital are strong. ${ }^{2}$

Our model bridges and extends two strands of previous literature. One is an older literature on knowledge-based assets and internalization. This literature emphasizes the jointness property of knowledge capital - the ability of the firm to use knowledge capital fully in multiple locations at the same time (Markusen's 2002 knowledge-capital model) - which leads to multi-plant economies of scale. This literature suggests that the jointness property also leads to the problem of asset dissipation - knowledge assets are easily transferred but also easily absorbed by a licensee - and so a preference by the firm for FDI. Formal models include Horstmann and Markusen (1987), Ethier and Markusen (1996), Markusen (2001), Fosfuri, Motta, and Rønde (2001), and Glass and Saggi (2002). The other strand is a more recent literature focused around the Grossman-Hart-Moore property-rights approach (Grossman and Hart 1986; Hart and Moore 1990) which emphasizes the connection between ownership and control for physical capital. Important papers include Grossman and Helpman (2002, 2004), Antrás (2003, 2005), and Feenstra and Hanson (2005). Our paper is also related to Arora (1996), who argues that control of a complementary asset may be used in technology licensing agreements to prevent the licensee from 'misusing' the tacit

1 See Morck and Yeung $(1991,1992)$ for evidence on the importance of information-related intangible assets in the FDI decision. For events in which firms do transfer technology abroad, articles by Davidson and McFetridge (1984), Mansfield and Romeo (1980), Teece (1986), and Wilson (1977) show technology is more likely to be transferred internally within the firm by R\&D-intensive firms producing new and technically complex products.

2 Smith (2001) finds that stronger foreign patent rights increase US firms' transfers of knowledge more by licensing than by affiliate sales. Yang and Maskus (2001) find that countries with stronger patent rights attract larger arm's-length volumes of licensed technology, although licensing is not compared with FDI. Maskus, Saggi, and Puttitanum (2005) find that stronger patent protection increases the probability of inward FDI and has very little effect on licensing; but they note that this overall finding is driven by high-technology sectors, and that lower-technology sectors have the opposite result (stronger protection increases licensing more than FDI). 
knowledge received from the licensor. Data on licensing contracts to India show support for this hypothesis.

\section{The model}

A multinational firm (MNE) in the North, denoted as $M$, plans to produce a product (either intermediate or final) in the South, owing to cost advantages of manufacturing there. There are two periods of production, $t=1,2$, and there is no discounting. Production in the South requires the services of a local agent/manager, denoted as $A$, and two types of asset services: physical capital and knowledge capital / intellectual property. For production to occur in either period, a physical capital investment in the amount $K$ must be undertaken at the beginning of $t=1$. Within any given industry, the value of $K$ is fixed and exogenous. ${ }^{3}$ Either $M$ or $A$ can undertake this investment and, by so doing, becomes the 'owner' of the physical capital. The price of $K$ is one. By contrast, only $M$ owns the knowledge capital initially; the amount of knowledge capital that $M$ owns is a fixed and exogenous amount equal to $S$.

At the beginning of $t=1, M$ makes a once-for-all choice between two possible organizational forms: FDI or outsourcing. With FDI, $M$ acquires (and owns) the physical capital used for production in the South and employs $A$ under a sequence of one-period employment contracts to manage a production process utilizing $M$ 's capital. $A$ 's hiring occurs at the beginning of $t=1$ and $A$ 's employment contract is renegotiated at the beginning of $t=2 . M$ also decides each period how much knowledge capital to transfer to $A$ to be utilized in production.

With outsourcing, $A$ acquires (and owns) the physical capital, where capital acquisition again occurs at the beginning of $t=1$. $M$ signs a one-period licensing contract with $A$ that licenses an amount $s_{1}$ of $M$ 's knowledge capital to $A$ for use in production at $t=1$. This licensing agreement is renegotiated at the beginning of $t=2$, and an amount $s_{2}$ is transferred at $t=2$.

As in Grossman and Hart (1989), ownership of physical capital bestows control rights on the owner. Specifically, the owner can decide on the uses to which the capital can be put and can exclude access to the capital for any other uses at any time. That having been said, effort from the agent is often required to improve or maintain the efficiency (usefulness) of the physical capital. We shall make these points clear shortly when we specify the payoff functions of the players.

Knowledge (or intellectual) capital, by contrast, does not have the same excludability properties. The owner of knowledge capital may not be able to control to the same extent the uses to which the capital is put and to capture the returns that the knowledge capital generates. In essence, property rights to knowledge

3 The assumption that $K$ is exogenous is for simplicity and does not alter the results to follow. As will become clear, the important assumption is that investments must be undertaken at $t=1$ if production is to occur at $t=2$ without added capital costs. 
capital are harder to define and protect than is the case for physical capital. To capture these features of knowledge capital, we assume that, at $t=1$, there exists a fraction $\sigma<1$ of $S$ that is 'explicit knowledge' in the sense that its use can be defined in a $t=1$ licensing agreement. In this sense, the fraction $\sigma$ of $M$ 's knowledge capital can be 'owned' in the same way as physical capital is owned. A fraction $1-\sigma$ of $S$ is 'tacit knowledge' and is not contractible at $t=1$ in the sense that its current and future uses cannot be controlled by $M$ in a $t=1$ licensing agreement. ${ }^{4}$ The value of $\sigma$ is assumed to be exogenous to the firm and can be thought of as capturing either characteristics of the knowledge capital or a characteristic of the legal regime of the country in which $M$ is contracting. For simplicity, we assume that, at $t=2$, all knowledge capital is contractible.

Note that this set of assumptions allows a simple characterization of the environment in which $M$ and $A$ operate. Specifically, the values of $K, S$, and $\sigma$ completely define the environment - characteristics of the relevant industry/ product - under consideration. The values of $K$ and $S$ give the physical relative to knowledge capital intensity of the industry, while $\sigma$ gives features of the appropriabilty of $M$ 's knowledge asset. Subsequent analysis will consider how variation in the economic environment - variation in $(K, S, \sigma)$ - affects the observed pattern of outsourcing and FDI.

For any given $K$ and knowledge asset $s_{i}$ for $i=1,2$, the maximum gross surpluses that accrue to $M$ and $A$ from utilizing $K$ and $s_{i}$ at $t=1$ and at $t=2$ are $U_{1}\left(K, s_{1}\right)$ and $U_{2}\left(K, s_{2}\right)+V(e \mid K)$, respectively. In the latter expression, $e$ is $A$ 's effort during $t=1$ that affects the return to capital, $V(e \mid K)$, in $t=2$, where $V(e \mid K)$ is an increasing, concave function of $e$ for any given value of $K$. In what follows, we assume that $U_{t}(K, S)$ is increasing in both $K$ and $S$ and that $U_{1}\left(K, s_{1}\right)$ and $U_{2}\left(K, s_{2}\right)+V(e \mid K)$ are bounded above. We also assume that $U_{t}(K, 0)>0$ for all $K>0$, so that the agent has alternative uses for $K$ even if $s_{t}=0$. In this way, we allow the possibility that $K$ can be used either for producing $M$ 's product or for some alternative purpose benefiting $A$ (e.g., $K$ can be used for $A$ 's private benefits). We assume that producing $M$ 's product always yields higher payoffs than any alternative use when $s_{t} \geq \sigma S$, but the alternative payoff could be higher if $s_{t}<\sigma S$.

There is a perfectly elastic supply of agents with opportunity cost $W \geq 0$ in each period. However, the party not owning capital at $t=1$ is not able to raise

4 As an example, Nike can license use of trademarks and brand names to a contract manufacturer and reasonably cheaply control the use of these items and capture licensing fees. These elements would constitute explicit knowledge capital. Nike may also communicate design concepts and market knowledge. This information would constitute implicit knowledge capital in that it is more difficult to control fully and to capture all returns from its use. Values of $s_{i}<\sigma S$ imply that some or all of the explicit knowledge capital - some or all of the trademarks and branding are transferred to the agent. A value of $s_{i}>\sigma S$ implies that, in addition, some amount of implicit knowledge - some of the design concepts and market information - are also transferred to the agent. See, however, Arora (1996) for a discussion of how part of the 'tacit knowledge' might also be transferred through arm's length contracts, if it can be bundled with patented codified part of knowledge, in which case $\sigma$ would be higher. 
the amount $K$ sufficiently quickly to produce alone at $t=2$. This fact produces a (potential) specific relationship between $M$ and $A$ at $t=2 .{ }^{5}$ In this case, the $t=2$ surplus is allocated based on the Nash bargaining solution. Both $A$ and $M$ are risk neutral and make choices to maximize expected income.

We assume that, at $t=1, M$ has access to perfect capital markets, while $A$ has only limited ability to borrow against future income to finance capital $K$ and consumption $W$ (i.e., $W$ is both an opportunity cost and a subsistence requirement). Specifically, under outsourcing $A$ can only cover a fraction $\gamma \in$ $(0,1]$ of $t=1$ costs $(K+W)$ via the capital market. The remainder must be covered out of $t=1$ revenues. As will be seen later, this inability on $A$ 's part to borrow against future income limits $M$ 's ability to extract $t=2$ surplus from $A$ via the initial licensing agreement. It also forces $M$ to bear some of the costs of $A$ 's capital investment.

Throughout our analysis, we shall maintain the following assumption:

Assumption 1. There exist values $\bar{K}, \underline{K}$ such that (i) for all $\underline{K} \leq K \leq$ $\bar{K}, U_{2}(K, 0)+V(0 \mid K)-(1+\gamma) W-\gamma K \geq 0$, with strict equality at $K=\underline{K}$ and (ii) for all $K \geq \bar{K}, U_{2}(K, 0)+V(0 \mid K)-(1+\gamma) W-\gamma K \leq 0$ and strictly decreasing in $K$.

Part (i) of assumption 1 requires that, for small values of physical capital, the agent can go it alone - operate with no knowledge capital - at $t=2$ and still capture sufficient value to cover all costs of operation. As will be seen, this condition is related to the participation constraint for the agent. Part (ii) of assumption 1 is a mild regularity condition. Recall that $U_{2}(K, 0)+V(0 \mid K)$ is bounded above in $K$. As a result, there must exist some $\bar{K}$ value such that $U_{2}(K, 0)+V(0 \mid K)-(1+\gamma) W-\gamma K \leq 0$ for all $K \geq \bar{K}$. Part (ii) amounts to an assumption that this $\bar{K}$ value is unique.

Notice that we allow $V(e \mid K)$ to be either positive or negative. ${ }^{6}$ For instance, $V(e \mid K)$ could be the depreciation (repair) cost of $K$ in $t=2$, as, for example, $V(e \mid K)=-\delta K(1-e)^{2}<0$, and $e$ simply reduces this cost. Or $e$ could be $A$ 's effort to find additional use for $K$ that adds value in $t=2$. For instance, a by-product may be produced with $K$, in addition to the product already being produced using $K$, in which case $V(e \mid K)>0 .^{7}$

To summarize, the timing of the game is as follows.

At the beginning of $t=1, M$ chooses between FDI and outsourcing. If $M$ chooses FDI, then $M$ offers $A$ an employment contract involving payment to $A$ of $w_{1}$; if $M$ chooses outsourcing, $M$ and $A$ negotiate a contract involving a

5 This is relevant in the case of oursourcing, where the agent, who owns $K$, can demand the sharing of returns from using $S$ in $t=2$.

6 If $V(e \mid K)<0$, however, $U_{2}(K, 0)$ will need to be high enough to satisfy (ii).

7 This positive $V$ is to be distinguished from $A$ 's using $K$ for private benefits that reduces the return of $K$ to $M$. For convenience and to capture the idea that effort is more important to improve or maintain the usefulness of physical capital, we assume $V$ does not depend on $s$. This is certainly the case, for instance, if $V$ represents the depreciation of $K$. This assumption is not essential for the main insights of our analysis. 
transfer to $A$ of knowledge capital, $s_{1}$, and a licensing payment from $A$ to $M$ of $l_{1}$. In either case, should $A$ accept the contract, $A$ chooses an effort level $e$ and $M$ chooses the level of knowledge capital to use (this level is determined by the licensing contract under outsourcing). Gross surplus $U_{1}\left(K, s_{1}\right)$ is then realized and payments are made.

At the beginning of $t=2, M$ offers $A$ a second employment contract involving a payment $w_{2}$ under FDI. If $A$ accepts, $M$ again chooses a level of knowledge capital utilization for $A$. Under outsourcing, $M$ and $A$ negotiate, via Nash bargaining, a second contract involving a transfer to $A$ of intellectual capital, $s_{2}$, and a licensing payment from $A$ to $M$ of $l_{2}$. Gross surplus $U_{2}\left(K, s_{2}\right)+V(e \mid K)$ is then realized and payments are made.

In all cases, the equilibrium levels of $e, s_{1}, s_{2}$ are the result of subgame perfect Nash equilibrium strategy choices by $A$ and $M$, and $U_{i}$ is sufficiently large relative to $K$ and $W$ that in equilibrium it is profitable for $M$ to choose either FDI or outsourcing.

\section{Analysis}

To provide a benchmark, we begin by characterizing solutions to the complete contracting case where contracting on $e$ and $s_{i} \in[0, S]$ are feasible. The complete contracting solution solves

$$
\max _{e, s_{1}, s_{2}} U_{1}\left(K, s_{1}\right)+U_{2}\left(K, s_{2}\right)+V(e \mid K)-e-K .
$$

Since both $U_{1}\left(K, s_{1}\right)$ and $U_{2}\left(K, s_{2}\right)$ increase in $s$, and $M$ can control the use of $S$ with complete contracting, $M$ chooses $s_{1}=s_{2}=S$. The level of effort, $e^{*}$, satisfies

$$
V_{e}\left(e^{*} \mid K\right)=1 .
$$

We next return to our model of incomplete contracting. After analyzing the FDI contract equilibrium and then the outsourcing equilibrium, we compare equilibrium payoffs for $M$ and determine the situations in which $M$ prefers FDI to outsourcing.

\subsection{Equilibrium under FDI}

We begin by analyzing the equilibrium contract at $t=2$. Since $M$ owns the physical asset under FDI, $M$ can control the use of $K$ at $t=2$. Thus, $M$ can prevent $A$ from using $S$ for purposes other than $M$ 's project in $t=2$. Consequently, $A$ 's outside option is simply $W$, and, since $U_{2}\left(K, s_{2}\right)$ is increasing in $s_{2}, M$ chooses knowledge capital transfer of $s_{2}^{F}=S$. As a result, the contract that $M$ offers $A$ involves a payment $w_{2}^{F}=W$. $M$ 's payoff at $t=2$ is, therefore, $\pi_{M 2}^{F}=U_{2}(K, S)+V(e \mid K)-W$. 
At $t=1, M$ will optimally choose $s_{1}^{F}=S$, since $U_{1}\left(K, s_{1}\right)$ is increasing in $s_{1}$ and the payoff at $t=2$ is independent of the value of $s_{1}$. Further, since effort is costly for $A$ and $A$ 's compensation at $t=2$ is independent of $e, A$ will choose $e^{F}=0$. Recognizing this, $M$ offers a payment of $w_{1}^{F}=W$. M's two-period payoff from choosing FDI is thus

$$
\Pi_{M}^{F}=U_{1}(K, S)+U_{2}(K, S)+V(0 \mid K)-2 W-K .
$$

We summarize this discussion below.

LEMma 1. Under the FDI option, the unique equilibrium contract pair involves (i) transfers of knowledge capital of $s_{1}^{F}=s_{2}^{F}=S$, and (ii) wage payments to A of $w_{1}^{F}=w_{2}^{F}=W$. Under this contract, $A$ chooses effort level $e^{F}=0$ and $M$ 's equilibrium payoff is $\Pi_{M}^{F}$ given in equation (3).

Note that, under FDI, the equilibrium contract is a standard wageemployment contract. The contract allows $M$, via control of physical capital, to control the use of $M$ 's knowledge capital. ${ }^{8}$ The agent employee exerts no (extra) effort in improving (maintaining) physical capital and undertakes no tasks other than those involved in working directly for $M$. The inefficient choice of $e$ by $A$ obtains because $M$ cannot commit to compensating $A$ for its investment in $e$. As such, the contract exhibits the often discussed features of an insourced activity: low-powered incentives (and so problems of lower effort) but control over asset use.

\subsection{Equilibrium under outsourcing}

Unlike the case of FDI, under outsourcing $A$ now owns the physical capital, while $M$ still owns the knowledge capital. This ownership difference impacts both the ability of $M$ to control the use of knowledge capital via control of physical capital and the incentives that $A$ has to invest in improving (maintaining) physical capital. Regarding the former, since $A$ owns the physical capital and so can control the uses of $K, A$ can credibly threaten to use $K$ for own purposes in any period. This implies that, at $t=2$, the Nash bargaining solution must account for $A$ 's alternative uses of $K$ - these uses form $A$ 's threat point in the bargaining - and compensate $A$ appropriately. As to the latter, since $A$ now owns the physical capital, $A$ has greater incentives to improve (maintain) it.

To see how these effects play out, consider the $t=2$ contract. When $s_{1} \geq$ $\sigma S$, should $M$ and $A$ fail to reach an agreement at $t=2$, then $A$ can use the intellectual capital not controlled by $M$ and $A$ 's own physical capital for other uses. In particular, $A$ can use $K$ and $s_{1}-\sigma S$ to generate return $U_{2}\left(K, s_{1}-\sigma S\right)+$ $V(e \mid K)$, through either producing an imitation of $M$ 's product, or putting the assets for some alternative purpose, or both. Of course, $A$ can also choose not

$8 M$ will also require $A$ to use $K$ only for $M$ 's project. Otherwise, $A$ may use $K$ for its own alternative purpose, given that he receives a fixed wage payment. 
to produce and obtain $W$. From assumption 1, we have that $U_{2}\left(K, s_{1}-\sigma S\right)+$ $V(e \mid K) \geq U_{2}(K, 0)+V(0 \mid K)>W$, implying that $A$ 's disagreement payoff at $t=2$ is $U_{2}\left(K, s_{1}-\sigma S\right)+V(e \mid K)$. The disagreement payoff for $M$ in $t=2$ is 0 .

Since the maximum joint surplus for $M$ and $A$ if they reach agreement is $U_{2}(K, S)+V(e \mid K)>U_{2}\left(K, s_{1}-\sigma S\right)+V(e \mid K)$, it is in each party's interest to agree on a contract at $t=2$. According to the Nash bargaining solution, which splits the surplus equally between the two, $M$ 's and $A$ 's payoffs are, respectively,

$$
\begin{aligned}
& \pi_{M 2}^{O}=\frac{U_{2}(K, S)-U_{2}\left(K, s_{1}-\sigma S\right)}{2} \\
& \pi_{A 2}^{O}=\frac{U_{2}(K, S)+U_{2}\left(K, s_{1}-\sigma S\right)}{2}+V(e \mid K) .
\end{aligned}
$$

Anticipating this fact, during $t=1$ agent $A$ will choose $e$ to maximize

$$
\pi_{A 2}^{O}-e=\frac{U_{2}(K, S)+U_{2}\left(K, s_{1}-\sigma S\right)}{2}+V(e \mid K)-e,
$$

so that the equilibrium $e$ under outsourcing is $e^{O}=e^{*}$, the efficient $e$ as defined in equation (2).

Turning next to the $t=1$ contract, since there is a perfectly elastic supply of agents at $t=1$ and knowledge capital is fully contractible for $s_{1} \leq \sigma S, M$ captures all incremental returns to the use of knowledge capital for $s_{1} \leq \sigma S$ : for $s_{1} \leq \sigma S, M$ 's licensing revenues at $t=1$ are $U_{1}\left(K, s_{1}\right)-(1-\gamma)(K+W) .{ }^{9}$ Since $U_{1}(\cdot)$ is increasing in $s_{1}, M$ will choose to license at least $\sigma S$ units of knowledge capital. Since $M$ cannot commit to transferring any $s_{1}>\sigma S\left(s_{1}>\sigma S\right.$ is not contractible) or capture returns at $t=1$ from doing so, and since $M$ 's return at $t=2\left(\pi_{M 2}^{O}\right)$ is decreasing for $s_{1}>\sigma S$, the equilibrium licensing contract at $t=1$ has $s_{1}^{O}=\sigma S$. The licensing payment by $A$ to $M$ is

$$
l_{1}^{O}=U_{1}(K, \sigma S)-(1-\gamma)(K+W) .
$$

From (5) and (6), and recalling that in $t=1$ agent $A$ receives $U_{1}(K, \sigma S)$ but has capital $\operatorname{cost} K$ and effort $\operatorname{cost} e^{*}$, we conclude that, under the equilibrium pair of outsourcing contracts, $A$ 's payoff is

$$
\begin{aligned}
\Pi_{A}^{O} & =\left.\pi_{A 2}^{O}\right|_{e=e^{*}}-e^{*}+U_{1}(K, \sigma S)-K-l_{1}^{O} \\
& =\frac{U_{2}(K, S)+U_{2}(K, 0)}{2}+V\left(e^{*} \mid K\right)-e^{*}-K+(1-\gamma)(K+W) .
\end{aligned}
$$

9 Recall that A can borrow against future income only to cover a fraction $\gamma$ of first-period capital and consumption costs $(K+W)$. The rest must be covered out of first-period revenues and hence reduces $M$ 's maximum licensing fee by $(1-\gamma)(K+W)$. 
Since $A$ has an opportunity cost of $2 W$ to work with $M$ under the licensing contract, in equilibrium it is required that $\Pi_{A}^{O} \geq 2 W$, which we assume to hold. $M$ 's equilibrium payoff from outsourcing is, from (4) and (6),

$$
\Pi_{M}^{O}=\frac{U_{2}(K, S)-U_{2}(K, 0)}{2}+U_{1}(K, \sigma S)-(1-\gamma)(K+W) .
$$

The results for the outsourcing contract are summarized below.

LEMMA 2. Under the outsourcing option, the unique equilibrium contract pair is

$$
\begin{aligned}
& l_{1}^{O}=U_{1}(K, \sigma S)-[(1-\gamma)(K+W)], s_{1}^{O}=\sigma S \\
& l_{2}^{O}=\frac{U_{2}(K, S)-U_{2}(K, 0)}{2}, s_{2}^{O}=S .
\end{aligned}
$$

The equilibrium effort choice by $A$ is $e^{*}$. Equilibrium payoffs for $A$ and $M$ are $\Pi_{A}^{O}$ and $\Pi_{M}^{O}$, given in equations (7) and (8).

Note that outsourcing generates efficient effort by the agent but leads to inefficient transfer of intellectual capital. Also, because of $A$ 's limited access to capital markets, $M$ has a limited ability to extract payment at $t=1$ from $A$ 's hold-up surplus at $t=2 .{ }^{10}$

\subsection{Equilibrium choice of organization form}

To determine $M$ 's choice between FDI and outsourcing, one need only examine the payoff difference under the two options. From (3) and (8), this difference is given by

$$
\begin{aligned}
\Pi_{M}^{F}-\Pi_{M}^{O}= & {\left[U_{1}(K, S)-U_{1}(K, \sigma S)\right] } \\
& +\left[\frac{U_{2}(K, S)+U_{2}(K, 0)}{2}+V\left(e^{*} \mid K\right)-W\right] \\
& -\left[V\left(e^{*} \mid K\right)-V(0 \mid K)\right]-\gamma(W+K) .
\end{aligned}
$$

In (9), the term $U_{1}(K, S)-U_{1}(K, \sigma S)>0$ represents the gain from FDI due to better knowledge capital transfer. The term

$$
\frac{U_{2}(K, S)+U_{2}(K, 0)}{2}+V\left(e^{*} \mid K\right)-W>U_{2}(K, 0)+V\left(e^{*} \mid K\right)-W>0
$$

10 Specifically, the capital market restriction leads to a transfer from $M$ to $A$ at $t=1$ in the amount of $(1-\gamma)(K+W)$. Note, however, from (7) and (8), that this transfer is lump sum and so does not result in an efficiency loss. 
represents the increased surplus accruing to $M$ due to avoidance of hold-up under FDI created by the fact that $M$ owns the $K$ under FDI. ${ }^{11}$ The third term, $-\left[V\left(e^{*} \mid K\right)-V(0 \mid K)\right]$, represents the loss to $M$ due to the lower effort under FDI. The final term, $-\gamma(W+K)$, reflects the ability of $M$ to recapture some of $A$ 's second-period hold-up rents under outsourcing by requiring $A$ to finance a portion of $(W+K)$ in the first period. When $\Pi_{M}^{F}-\Pi_{M}^{O}>0, M$ chooses FDI; when $\Pi_{M}^{F}-\Pi_{M}^{O}<0, M$ chooses outsourcing.

In order to characterize the situations - industry/product environments $(K, S, \sigma)$ - in which outsourcing and FDI occur, it proves useful to distinguish industries - $(K, S)$ pairs - by their factor intensity and their scale. As is typical, factor intensity for an industry is defined by the value of $K / S$ : Industries with large values of $K / S$ are physical capital-intensive industries, while those with low values of $K / S$ are knowledge capital-intensive industries. The scale of an industry is defined by the value of $U_{1}(K, S)+U_{2}(K, S)$ : Industries with larger values of $U_{1}(K, S)+U_{2}(K, S)$ are large-scale industries and industries with smaller values of $U_{1}(K, S)+U_{2}(K, S)$ are small-scale industries. This distinction allows us to consider how the outsourcing decisions vary across industries of similar scale but different factor intensities and across industries of similar factor intensity but differing scales. Our result is as follows (for a proof, see the appendix):

Proposition 1. For industries of sufficiently small-scale, FDI is the organizational mode, independent of factor intensity. In larger-scale industries, FDI is the organizational mode for industries that are knowledge capital-intensive, while outsourcing is the organizational mode for industries that are physical capital-intensive. For any industry, the larger $\sigma$, is the more attractive is outsourcing.

To see the intuition for this result, recall, from above, that there are basically three forces at work determining organizational mode. The first is the limited contractibility of knowledge capital under outsourcing: the more important knowledge capital is, the more valuable is the control over knowledge capital that FDI affords. The second is the potential costs from hold-up under outsourcing: the greater are the $t=2$ returns that the outsourcing agent captures due to hold-up, the more attractive is FDI (which avoids hold-up). Finally, there are the positive incentive effects created by outsourcing. For industries in which knowledge capital is insignificant - the physical capital-intensive industries - the first force becomes largely irrelevant. The value of FDI for hold-up avoidance is also reduced. This is particularly so the larger the scale of the industry. For large-scale industries, the outsourcing agent's hold-up income pays for a large share of all capital costs. The result is that, for industries that are sufficiently physical capital-intensive and of sufficiently large-scale, outsourcing

11 That is, under FDI, $M$ needs to pay $A$ only an amount equal to $W$ in $t=2$, whereas under outsourcing $A$ will obtain $\frac{U_{2}(K, S)+U_{2}(K, 0)}{2}+V\left(e^{*} \mid K\right)$ in $t=2$, owing to its ownership of $K$ and that it can hold up $M$ in demanding a higher payoff. 
rather than FDI is the chosen organizational mode. For these industries, the costs under outsourcing from limited contractibility of knowledge capital and from hold-up are small and so the benefits of improved incentives under outsourcing dominate.

The reverse is true for industries that are either small-scale or that have significant amounts of knowledge capital - the knowledge capital-intensive industries. In the latter case, the cost of limited contractibility of knowledge capital under outsourcing now loom large, even if hold-up costs are small, and dominate any incentive benefits that outsourcing bestows. The result is that such industries are organized using FDI. For small-scale industries, the incentive benefits are generally small and the hold-up costs relatively large under outsourcing and so, again, FDI is the organizational choice.

As a coarse prediction of our model, we should expect to observe outsourcing in industries that are large-scale, physical capital intensive, and such that knowledge capital is easily controlled under a licensing agreement. We should expect to observe FDI in industries that are either small scale or knowledge capital intensive and such that knowledge capital is difficult to control under a licensing agreement. Consistent with these predictions, we see the manufacturing of standard electronics equipment such as DVD players, CD players, and regular TVs outsourced, as are items like Crocs footwear and Nike or Adidas athletic shoes. In all of these cases, production is physical capital-intensive and existing knowledge capital is easily controlled under a licensing agreement. These products are also produced on a large scale. By contrast, Crocs manufactures crosslite in its own facilities because manufacture of crosslite requires knowledge of the crosslite formulation, the knowledge capital that generates most of the return for Crocs. ${ }^{12}$

Our theoretical findings have other potentially testable implications as well. First, consider a comparison between two firms of similar scale but such that one has more owned relative to outsourced foreign operations than the other (which has more outsourced relative to owned foreign operations). The proposition implies that the former firm must have relatively more products/activities that are knowledge capital intensive and/or have a lower $\sigma$ than does the latter firm. Since each of the FDI activities, all else equal, will have a higher return at $t=1$ $\left(U_{1}(K, S)>U(K, \sigma S)\right)$ and a lower replacement value (physical capital value plus the value of explicit intellectual capital), the former firm - the firm with relatively many owned foreign operations - will have a higher Tobin's $q$ than does the latter. ${ }^{13}$ As a result, controlling for explicit knowledge capital, we should observe

12 Given Intel's early experience with licensing of chip manufacture to AMD, a similar argument presumably underlies Intel's decision to manufacture chips in owned manufacturing facilities.

13 Recall that Tobin's $q$ is defined as

$$
q=\frac{\text { market value of the firm }}{\text { replacement cost of firm assets }} .
$$


a positive correlation between number of owned foreign operations and Tobin's $q$. This prediction is the counterpart of the earlier internalization hypothesis and is supported by existing empirical evidence (see Markusen 1995, 2002; Caves 2007). As an example, Morck and Yeung (1991) show that, after controlling for explicit knowledge capital such as R\&D and advertising expenditures, firms with more owned foreign subsidiaries have a higher Tobin's $q .{ }^{14}$

Our results also have implications for the choice of organizational mode over the product life cycle. Typically, the product life cycle is characterized in terms of recently innovated products being relatively intensive in intellectual assets and established products being relatively intensive in physical assets. Under this interpretation, a recently introduced product is one with $S / K$ large and so its manufacturer is likely to choose FDI; an established product is one with $S / K$ small and so its manufacturer is likely to choose outsourcing. Again, we have some observations of this pattern in the data. Sharp, for instance, produces it's latest flat-panel and plasma TVs for Europe in an owned facility in Eastern Europe. Its standard TVs and older flat-panel models are produced by outsourced manufacturers in Asia.

Markets in which technologies evolve rapidly, so that any existing knowledge capital depreciates quickly, are ones that the model also predicts should feature more outsourcing. The reason is that markets with rapid technological change will feature low values for $U_{2}(K, S)-W$, as rents from knowledge capital decline quickly with time. Therefore, the hold-up problem that FDI solves is less severe in markets with rapid technological change. This makes outsourcing a more attractive option. Similarly, products that require highly skilled agents that are in scarce supply in the foreign country - products for which $W$ is large relative to $U_{2}(K, S)$ - are also more likely to be outsourced. Again, the reason is that the value that FDI generates in terms of reduced hold-up is lower, since the agent already captures a large share of second-period rents due to the high value of $W$.

To the extent that stronger intellectual property protection or contract enforcement is likely to lead to a higher $\sigma$, the proposition further suggests that outsourcing to a country is more likely, as it implements stronger intellectual property protection. Finally, note that the larger $\gamma$ is, the larger is the amount of the second-period surplus that $M$ can claim in the first-period outsourcing contract (and the larger is the share of physical capital costs borne by $A$ ). As a result, as $\gamma$ becomes larger, outsourcing becomes a more attractive option. Since low values of $\gamma$ are associated with greater capital market imperfections in the foreign country, FDI is more likely in countries with significant capital market imperfections, whereas outsourcing is more likely in countries with well-functioning capital markets.

14 Morck and Yeung are exploring a different issue than we are. They want to understand whether multinationality enhances a firm's Tobin's $q$. We take no stand on that issue but simply note that the positive correlation found by Morck and Yeung is what our model would predict. 


\section{Conclusion}

In this paper we have examined how the non-excludability of knowledge capital leads to the ownership of a complementary asset, in our case physical capital, as a means of protecting intellectual property. The result we find is that firms that are largely dependent on knowledge capital for their returns will protect these returns by engaging in FDI rather than outsourcing. The ownership of physical capital protects the returns of the complementary asset: knowledge capital. The cost of this ownership is weak incentives for firm management. Firms whose returns rely little on knowledge capital and mainly on physical capital outsource to provide stronger management incentives. Strong support for these predictions is found by Jinji, Zhang, and Haruna (2011).

\section{Appendix: Proof of proposition 1}

We can rewrite

$$
\begin{aligned}
\Pi_{M}^{F}-\Pi_{M}^{O}= & U_{1}(K, S)-U_{1}(K, \sigma S)+\frac{U_{2}(K, S)-U_{2}(K, 0)}{2} \\
& +U_{2}(K, 0)+V(0 \mid K)-W(1+\gamma)-\gamma K .
\end{aligned}
$$

Since $U_{i}\left(K, s_{i}\right)$ increase in $s_{i}$, we have $U_{1}(K, S)-U_{1}(K, \sigma S)>0$, and $U_{2}$ $(K, S)-U_{2}(K, 0)>0$. From assumption $1, U_{2}(K, 0)+V(0 \mid K)-(1+\gamma) W-$ $\gamma K \geq 0$ for all $K \in[K, \bar{K}]$. Therefore, when $K$ is sufficiently small, we must have $\Pi_{M}^{F}-\Pi_{M}^{O}>0$ : FDI is the preferred choice. This occurs either when $S$ is large but $K / S$ is small or when both $K$ and $S$ are small. The former is the case of a large-scale and knowledge capital-intensive industry, while the latter is the case of small-scale. For $K>\bar{K}, U_{2}(K, 0)+V(0 \mid K)-(1+\gamma) W-\gamma K<0$. For $S$ sufficiently small, the first two terms above are arbitrarily close to zero and so $\Pi_{M}^{F}-\Pi_{M}^{O}<0$ : outsourcing is the preferred choice. This is the case of large-scale, physical capital-intensive industries.

\section{References}

Antrás, Pol (2003) 'Firms, contracts, and trade structure,' Quarterly Journal of Economics $118,1375-418$

Antrás, Pol (2005) 'Incomplete contracts and the product cycle,' American Economic Review 95, 1054-71

Arora, Ashish (1996) 'Contracting for tacit knowledge: the provision of technical services in technology licensing contracts,' Journal of Development Economics 50, 233-56

Caves, Richard E. (2007) Multinational Enterprise and Economic Analysis, 3rd ed. (Cambridge: Cambridge University Press)

Chen, Yongmin, Ignatius J. Horstmann, and James Markusen (2008) 'Physical capital, knowledge capital and the choice between FDI and outsourcing,' NBER Working Paper No. 14515 
Davidson, William H., and Donald G. McFetridge (1984) 'International technology transactions and the theory of the firm,' Journal of Industrial Economics 32, 253-64

Ethier, Wilfred J., and James R. Markusen (1996) 'Multinational firms, technology diffusion and trade,' Journal of International Economics 41, 1-28

Feenstra, Robert C., and Gordon H. Hanson (2005) 'Ownership and control in outsourcing to China: estimating the property-rights theory of the firm,' Quarterly Journal of Economics 120, 729-61

Fosfuri, Andrea, Massimo Motta, and Thomas Rønde (2001) 'Foreign direct investments and spillovers through workers' mobility,' Journal of International Economics $53,205-22$

Glass, Amy J., and Kamal Saggi (2002) 'Multinational firms and technology transfer,' Scandinavian Journal of Economics 104, 495-513

Grossman, Sanford J., and Oliver D. Hart (1986) 'The costs and benefits of ownership: a theory of vertical and lateral integration,' Journal of Political Economy 94, 691-719

Grossman, Gene, and Elhanan Helpman (2002) 'Integration versus outsourcing in industry equilibrium,' Quarterly Journal of Economics 117, 85-120

Grossman Gene M., and Elhanan Helpman (2004) 'Managerial incentives and the international organization of production,' Journal of International Economics 63, 237-62

Hart, Oliver D., and John Moore (1990) 'Property rights and the nature of the firm,' Journal of Political Economy 98, 1119-58

Horstmann, Ignatius J., and James R. Markusen (1987) 'Licensing versus direct investment, a model of internalization by the multinational enterprise,' Canadian Journal of Economics 20, 464-81

Jinji, Naoto, Xingyuan Zhang, and Shoji Haruna (2011) 'Does Tobin's $q$ matter for firms' choices of globalization mode?' RIETI Discussion Paper Series 11-E-061

Mansfield, Edwin, and Anthony Romeo (1980) 'Technology transfer to overseas subsidiaries by U.S. firms,' Quarterly Journal of Economics 94, 737-50

Markusen, James R. (1995) 'The boundaries of multinational enterprises and the theory of international trade,' Journal of Economic Perspectives 9, 169-89

- (2001) 'Contracts, intellectual property rights, and multinational investment in developing countries,' Journal of International Economics 53, 189-204

- (2002) Multinational Firms and the Theory of International Trade (Cambridge, MA: MIT Press)

Maskus, Keith E., Kamal Saggi, and Thitima Puttitanun (2005) 'Patent rights and international technology transfer through direct investment and licensing,' in International Public Goods and Transfer of Technology under a Globalized Intellectual Property Regime, ed. Keith E. Maskus and Jerome H. Reichman (Cambridge: Cambridge University Press)

Morck, Randall, and Bernard Yeung (1991) 'Why investors value multinationality,' Journal of Business 64, 165-87

- (1992) 'Internalization: an event study,' Journal of International Economics 33, 41-56

Smith, Pamela (2001) 'Patent rights and bilateral exchange: a cross-country analysis of U.S. exports, FDI, and licensing,' Journal of International Economics 52, 411-39

Teece, David (1986) The Multinational Corporation and the Resource Cost of International Technology Transfer (Cambridge, MA: Ballinger)

Wilson, Robert W. (1977) 'The effect of technological environment and product rivalry on R\&D effort and licensing of inventions,' Review of Economics and Statistics 59, 171-78

Yang, G.F., and Keith E. Maskus (2001) 'Intellectual property rights and licensing: an econometric investigation,' Weltwirtschaftsliches Archiv 137, 58-79 